\title{
Mismatch repair deficiency: a step forward personalized medicine in endometrial cancer?
}

\author{
Chiara Della Pepa ${ }^{1}$, Susana Banerjee ${ }^{2}$, Angela George ${ }^{2,3}$
}

\begin{abstract}
Endometrial cancer (EC) is the most common female malignancy in the world, it has traditionally been classified into two subgroups based on histopathological features, however this dualistic classification does not take into consideration subtypes such as high-grade endometrioid EC. Recently, work performed as part of The Cancer Genome Atlas study has focused on molecular genomic classification of EC, with four distinct molecular subtypes described: 1. POLE ultramutated, associated with a good prognosis; 2 . Microsatellite instability (MSI) hypermutated; 3 . Copy number low and microsatellite stable; 4 . Copy number high, serous like, associated with a poor prognosis. The subgroup of patients with MSI is of particular interest for a number of reasons, including the use of tumour screening to identify patients with Lynch syndrome, the prognostic significance of MSI, and the potential therapeutic implications. This review will focus on the current knowledge in these areas and potential future directions.
\end{abstract}

Key words: endometrial cancer, Lynch syndrome, microsatellite instability, mismatch repair

\section{Introduction}

Endometrial cancer (EC) is the most common gynaecologic malignancy in the US with more than 60.000 expected new cases in 2016 [1], and the sixth most common female malignancy in the world. The incidence of EC is rising in all western countries, along with the prevalence of some of the major risk factors for $\mathrm{EC}$, including obesity, diabetes and hyper-estrogenism (including polycystic ovarian syndrome, tamoxifen use, nulliparity, early age of menarche, later age of menopause) [2]. Protective factors include the use of oral contraceptives and Mirena coils [3].

EC has traditionally been classified into two subgroups based on histopathological features. Type I (oestrogen-dependent) EC accounts for about $70-80 \%$ of cases and is associated with endometrioid histology, oestrogen-receptor

'Uro-Gynecology Department, Istituto Nazionale Tumori IRCCS-Fondazione G. Pascale, Napoli, Italy.

${ }^{2}$ Gynaecology Unit, Royal Marsden NHS Foundation Trust, Fulham Road London SW3 6JJ, UK.

${ }^{3}$ Cancer Genetics Unit, Royal Marsden NHS Foundation Trust,

Fulham Road London SW3 6JJ, UK.

Correspondence to: Chiara Della Pepa, MD

Dipartimento Uro-Ginecologico,

Istituto Nazionale Tumori IRCCS-Fondazione G. Pascale,

Via Mariano Semmola 52, 80131 Napoli, Italy.

Phone: +39 0815903637 - Fax: +39 0815903861

E-mail: chiaradellapepa@hotmail.it

CANCER BREAKING NEWS 2016;4(2):34-41

DOI: $10.19156 / \mathrm{cbn} .2016 .0016$
(ER) positivity and low histological grade. These ECs appear to arise from areas of endometrial hyperplasia. Conversely, Type 2 (oestrogen-independent) EC includes the 'non-endometrioid' histological subtypes such as serous, clear cell, carcinosarcoma, mucinous adenocarcinoma and squamous cell carcinoma; these are typically high-grade and ER negative or weakly positive [4].

However this dualistic classification does not take into consideration subtypes such as high grade endometrioid EC. Recently, work performed as part of The Cancer Genome Atlas study has focused on molecular genomic classification of EC, with four distinct molecular subtypes described:

1. POLE ultramutated, associated with a good prognosis,

2. Microsatellite instability (MSI) hypermutated,

3. Copy number low and microsatellite stable,

4. Copy number high, serous like, associated with a poor prognosis [5].

This classification system, while interesting, requires significant molecular profiling that is not yet widely performed for EC, but may become more common if there are clear therapeutic implications.

The subgroup of patients with MSI is of particular interest for a number of reasons, including the use of tumour screening to identify patients with Lynch syndrome, the prognostic significance of MSI, and the potential therapeutic implications. This review will focus on the current knowledge in these areas and potential future directions. 


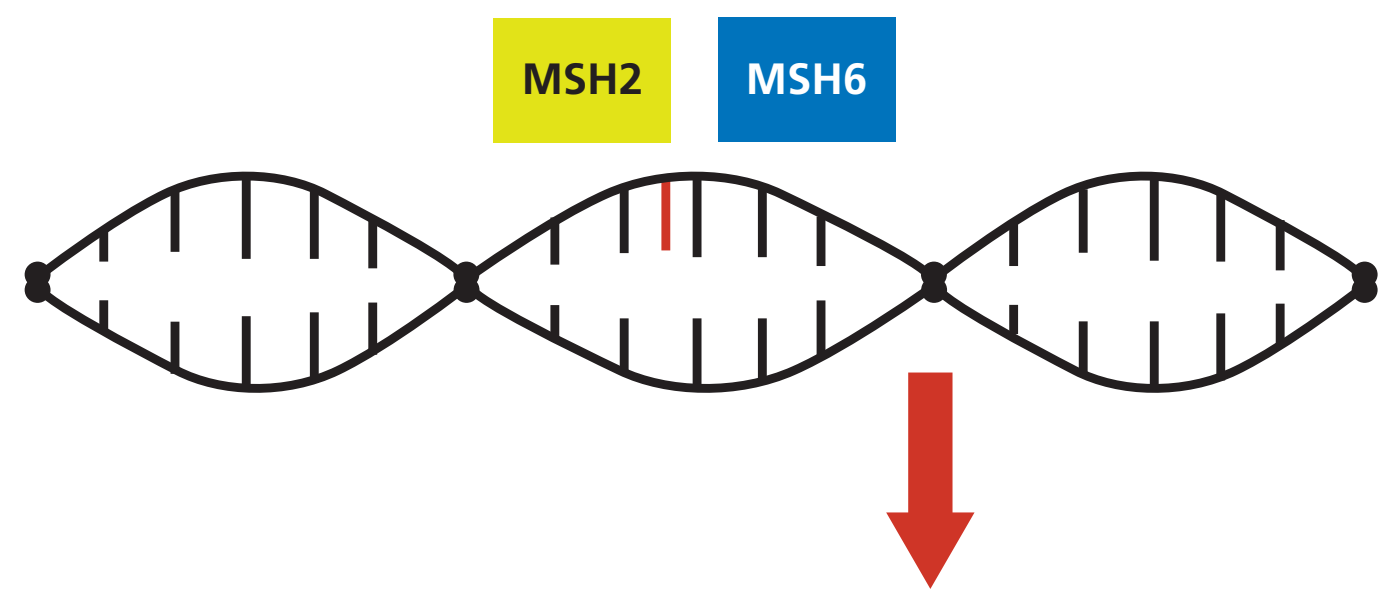

MLH1

PMS2

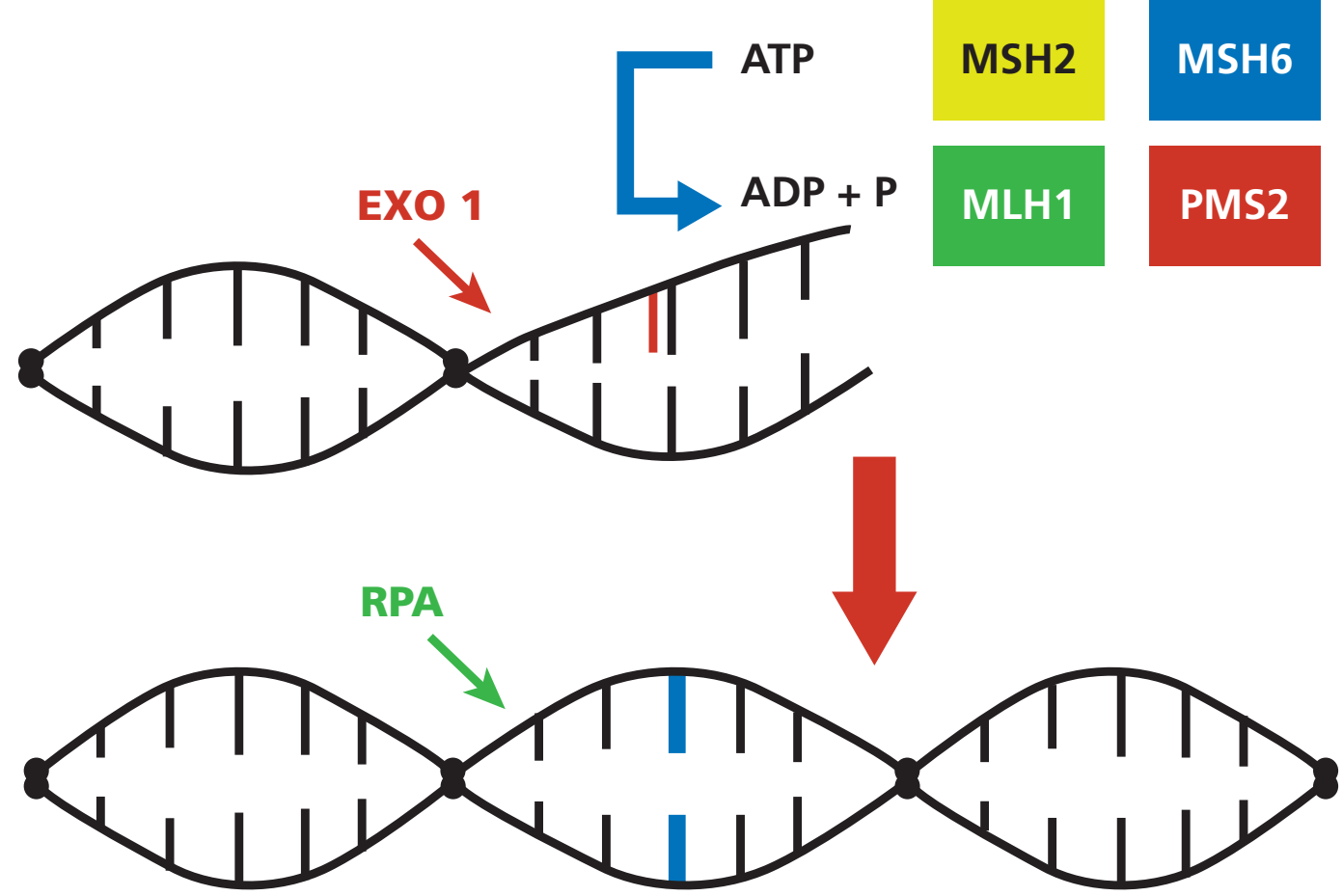

Fig. 1. Mismatch repair mechanism. The MMR pathway consists of several steps: MSH2-MSH6 detects mismatch and recruits MLH1-PMS2, hence the complex activates EXO1, exonuclease 1, which proceeds to the excision at the strand break. The resulting DNA gap is filled by RPA, replication protein A and DNA polymerase.

\section{MSI, MMR and Lynch syndrome}

The DNA mismatch repair (MMR) pathway is a crucial cellular process that comprises many proteins [6]. The final aim of the pathway is to identify and subsequently repair mismatched bases, likely to have arisen during DNA replication or chemical or physical damage (Figure 1). The result of defective DNA MMR is a phenotype called MSI; the MSI condition is associated with continuous insertion or deletion of short, repetitive sequences of DNA known as microsatellites, which are found across the genome [7]. High levels of MSI are found in the tumours of individuals with an inherited mutation in an MMR gene (Lynch syndrome); or those with somatic changes, the most common of which is promoter hypermethylation of MLH1 $[8,9]$. 
Four genes have been so far identified in the etiology of the MMR deficiency:

- MLH1 (mutL homologue 1) [10]

- MSH2 (mutS homologue 2) [11]

- MSH6 (mutS homologue 6) [12]

- PMS2 (post-meiotic segregation increased 2) [13] so named because of their homology to the E. coli MMR genes [11].

A germline mutation in any of these 4 genes results in Lynch syndrome.

\section{Detecting MSI and MMR}

The identification of individuals who may have Lynch syndrome can be performed by screening tumours for MSI or MMR deficiency using the following methods:

\section{IHC, immunohistochemistry}

IHC is a fast and readily available way to identify tumours with MMR deficiency. This tests protein expression for MLH1, MSH2, MSH6 and PMS2; MMR deficient tumours show complete loss of expression in one of several patterns. Tumours with loss of MLH1 and PMS2 will usually have an MLH1 mutation; while those with loss of MSH2 and MSH6 will have either an MSH2 or MSH6 mutation. Occasionally, isolated loss of MSH6 or PMS2 will occur with mutations in these genes. Although very easy to perform, the test can be variably reported or interpreted either due to different pathologists, or differing tumour fixation methods $[14,15]$, but has the benefit of indicating which MMR gene is most likely to be responsible for the phenotype.

\section{PCR-MSI testing}

This test is based on the use of special kits equipped with a panel of mononucleotides or dinucleotides repeats; the test is positive, indicating the presence of MSI, if two or more of the nucleotides markers show instability [16]. Of note, data in the literature demonstrate that neither IHC or MSI testing are $100 \%$ accurate in detecting MSI but the concordance rate is very high at $90-95 \%$ [17].

\section{Confirmatory Germline Testing}

Individuals found to have MMR deficient, or MSIhigh tumours can undergo germline testing for the four MMR genes to identify if the tumour changes are due to Lynch syndrome, or if it is due to somatic changes (such as MLH1 promoter hypermethylation). This testing is increasingly performed as part of a panel test using Next Generation sequencing, although PMS2 sequencing is challenging due to the presence of pseudogenes, and often requires separate long-range PCR sequencing [18-20].

\section{MSI and Lynch syndrome}

Lynch syndrome, also known as hereditary non-polyposis colorectal cancer (HNPCC) syndrome, was the first hereditary cancer syndrome identified and is associated with increased risks of cancers of the bowel, endometrium, ovary; and a number of other malignancies [21-27]. Women who carry a germline mutation in a Lynch syndrome gene have lifetime risks of EC of between 15-45\%, and of $15-55 \%$ for colorectal cancer, depending on the specific gene. Many female carriers will present with EC as their sentinel malignancy, with the median age of diagnosis in Lynch carriers of 45 years significantly younger than EC in those without Lynch syndrome $[28,29]$. Approximately $2 \%$ of newly diagnosed unselected EC patients have Lynch syndrome, with enrichment in those with synchronous ovarian and endometrial tumours, those $<50$ years at diagnosis, and nonobese women [30].

Since the discovery of the Lynch genes, criteria have been suggested to select those who should be referred for genetic testing. There are 2 main sets of criteria in use - the Amsterdam criteria and the Bethesda guidelines (Table 1). The Amsterdam criteria were first published in 1991 by the International Collaborative Group on Hereditary Non-Polyposis Colon Cancer (ICG-HNPCC), predating the discovery of the Lynch genes [31]. These were subsequently updated in 1998 after malignancies other than colorectal and endometrial cancers were confirmed to be part of the Lynch cancer spectrum [32]. The Bethesda guidelines were first produced in 1997, and subsequently updated in 2004 [33, 34]. In general, the Amsterdam criteria are felt to be more specific in selecting those who will have Lynch syndrome, whereas the Bethesda criteria are more sensitive, missing fewer potential carriers. Universal screening of all colorectal cancers for MMR deficiency or MSI is now standard in many countries, although such screening of ECs has lagged behind. This is despite recommendations by the NCCN that all ECs should undergo testing for MMR or MSI; while other countries have suggested an age limit of 60 or 70 years at diagnosis for those in whom routine tumour testing is performed, based on a number of studies assessing prevalence of mutations. Backes et al. reported their experience with a cohort of 140 patients (regardless of age) who underwent IHC analysis for MMRd; 30/140 (21\%) showed a MMRd phenotype, putting together the IHC evaluation, family history and age (cutoff 60 years old), the authors selected 15 patients, unfortunately only two of them underwent genetic testing which resulted negative in both cases [35]. Leenen evaluated 179 cases selected by age (cutoff 70 years old) and found a profile consistent with Lynch syndrome in 11 patients (6\%), of them 7 had a germ-line MMR mutation at the genetic testing [36]. 
Table 1. Diagnostic criteria for Lynch syndrome.

\begin{tabular}{|c|c|}
\hline Amsterdam I [31] & $\begin{array}{l}\text { - At least three family members must have histologically confirmed CRC } \\
\text { - One must be a first-degree relative of the other two } \\
\text { - At least two consecutive generations must be affected } \\
\text { - At least one of the CRC cases must have been diagnosed }<50 \mathrm{y} \\
\text { - Familial adenomatous polyposis must be excluded }\end{array}$ \\
\hline Amsterdam II [32] & $\begin{array}{l}\text { - At least three family members must have a cancer associated with HNPCC (CRC, EC, urothelial, } \\
\text { small bowel) } \\
\text { - One must be a first degree relative of the other two } \\
\text { - At least two successive generations must be affected } \\
\text { - At least one of the relatives with cancer associated with HNPCC must have been diagnosed }<50 \text { y } \\
\text { - Familial adenomatous polyposis must be excluded }\end{array}$ \\
\hline $\begin{array}{l}\text { Bethesda } \\
\text { guidelines [33] }\end{array}$ & $\begin{array}{l}\text { - Individuals with cancer in families that meet the Amsterdam Criteria } \\
\text { - Individuals with two HNPCC-related cancers (EC, OC, gastric, hepatobiliary, small bowel, TCCU, } \\
\text { synchronous and metachronous CRCs) } \\
\text { - Individuals with CRC and a first-degree relative with CRC and/or HNPCC-related extracolonic can- } \\
\text { cer and/or a colorectal adenoma; one of the cancers diagnosed at age }<45 \mathrm{y} \text {, and the adenoma diag- } \\
\text { nosed at age }<40 \mathrm{y} \\
\text { - Individuals with right-sided CRC with undifferentiated pattern (solid/cribriform) on histopathology } \\
\text { diagnosed at age }<45 \mathrm{y} \\
\text { - Individuals with signet-ring cell type CRC diagnosed at age }<45 \mathrm{y} \\
\text { - Individuals with adenomas diagnosed at age }<40 \mathrm{y}\end{array}$ \\
\hline $\begin{array}{l}\text { Revised Bethesda } \\
\text { guidelines [34] }\end{array}$ & $\begin{array}{l}\text { - CRC patients diagnosed at age }<50 \mathrm{y} \\
\text { - Presence of synchronous, metachronous CRC, or other HNPCC-associated tumors, regardless of age } \\
\text { - CRC patients diagnosed at age }<60 \text { y with MSI histology } \\
\text { - CRC diagnosed in one or more first-degree relatives with a HNPCC-related tumor, with at least one } \\
\text { of the cancers diagnosed at age }<50 \mathrm{y} \\
\text { - CRC diagnosed in two or more first-or-second-degree relatives with HNPCC-related tumors, regard- } \\
\text { less of age }\end{array}$ \\
\hline $\begin{array}{l}\text { Jerusalem } \\
\text { workshop [61] }\end{array}$ & $\begin{array}{l}\text { - All CRC patients }<70 \text { years old should be tested using IHC for the } 4 \text { DNA MMR gene products, or } \\
\text { alternatively, MSI } \\
\text { - A cost-benefit analysis is needed to determine the benefits and the costs of such a program }\end{array}$ \\
\hline
\end{tabular}

CRC: colorectal cancer; HNPCC: hereditary non polyposis colorectal cancer; IHC: immunohistochemistry; EC: endometrial cancer; MMR: mismatch repair; MSI: microsatellite instability; OC: ovarian cancer; TCCU: transitional call carcinoma of the urinary tract.

\section{Prognostic value of MMR deficiency}

Interest in the incidence and clinical implications of MMR in EC began in the late 1990s-early 2000s. Initially this was focused on the MMR deficiency observed in the context of Lynch syndrome, however it soon became clear that there were other mechanisms that resulted in an MMR deficiency, the most frequently observed of which in sporadic MSI EC is promoter hypermethylation of MLH1 [37], resulting in a lack of immunodetectable MLH1 protein expression [9]. Data in the literature suggest that sporadic
MMRd/MSI ECs accounts for 20-30\% of all ECs [38]. A recent work, exploring the potential relationship between body mass index and MMR status in a population of 1049 unselected ECs, reported that one or more MMR proteins were absent in 235 (22.4\%) of the cases, with combined loss of MLH1 and PMS2 the most common abnormality $(165 / 235,70 \%)$ [39].

A large number of studies have tried to address the clinicopathologic features of the MSI ECs, with most authors agreeing that such a phenotype is mainly associated with 
endometrioid histology [40-42], however data about further characteristics are largely inconsistent, especially in terms of prognostic value. In colorectal cancer the presence of the MSI phenotype has been recognized as a good prognostic marker [43], but this remains much less clear in EC, with the data largely conflicting [44-50]. A large meta-analysis about the prognostic relevance of MSI in EC, published in 2013 by Diaz-Padilla, included 23 studies (more than 40 were excluded due to absence of the required outcome data and/or the eligibility criteria) [51], with the authors failing to show a significant association between MSI and a worse overall survival (OS) $(\mathrm{p}=0.11)$ or disease free survival (DFS) $(\mathrm{p}=0.66)$. They concluded that the available data were inconclusive and not robust enough to support an association between MSI and clinical outcome. This may be partly due to the favourable prognosis of EC in general, particularly compared to other Lynch-associated malignancies. Women typically present with symptoms at an early stage, and the endometroid histology typical in Lynch endometrial cancer is itself associated with a better prognosis than non-endometroid subtypes. These women are at risk of developing second or subsequent malignancies, which can also impact significantly on their mortality [52]. The need for prospective studies, focused on prognosis with a homogeneous population, single method utilized to detect MMR deficiency or MSI, and appropriate follow-up was strongly stressed [51].

\section{MSI and immunotherapy}

The opportunity to identify the families with hereditary cancer predisposition and potentially prevent future cancers is an important aspect MMR/MSI testing, but recent evidences suggest that it may also identify a group of patients who would benefit from immunotherapy. Studies focused on colorectal cancer showed that MMRd is associated with an enhanced immune micro-environment, characterized by high infiltration of activated CD8 CTLs, cytotoxic T lymphocytes, and Th1 cells [53, 54]. A phase II study, evaluating the activity of pembrolizumab (inhibitor of the PD-1/PD-L1 axis, programmed death 1 and programmed death 1 ligand) in a cohort of 41 patients, reported response rates of $40 \%$ in the MMR deficient colorectal cancers, $70 \%$ in the MMR deficient noncolorectal tumours, and $0 \%$ in the MMR proficient tumours [55]. Howitt et al. analyzed a series of EC tumour samples for tumour infiltrating lymphocytes (TILs), PD-1 and PD-L1 expression and concluded that the POLE and MSI-high subtypes presented a strong enhancement of the immune microenvironment compared to the other EC subtypes [56]. These data, though preliminary, may sug- gest a rationale for testing the checkpoint inhibitors in MMR deficient ECs, and also strengthen the call for universal screening of endometrial tumours for MSI/MMR deficiency.

The presence of MMR may also impact on response to chemotherapy. In vitro studies have suggested that MMR gene mutations may impair response of tumour cells to platinum agents, the primary component of treatment for first line chemotherapy in EC. Platinum agents form covalent bonds with both strands of the DNA molecule, thereby activating the MMR system to begin repairing the resulting DNA damage. When over-activated, or if it fails to repair the DNA damage, apoptosis is initiated by the MMR system. It has been postulated that in the presence of an MMR mutation, the DNA damage is not recognized and tumour cells evade apoptosis [57]. In vivo studies of platinum in women with an MMR mutation have been conflicting, however the studies have been very small, and larger studies are required to examine this [58, 59]. For women with MSH2 mutations, there may be a role of oxidative damage-inducing drugs, such as methotrexate. In the absence of functional MSH2 protein, cells treated with methotrexate had an increase in $8-\mathrm{OHdG}$ oxidative lesions, incompatible with cell survival, while in cells with functional MSH2 these lesions are quickly corrected [60]. This synthetic lethality was not present in those with MLH1 deficient cells, and it is a very interesting area for future research.

\section{Our early experience}

In our department, the Uro-Gynaecology Unit at the National Cancer Institute of Naples, we have very recently started to perform IHC for MMR deficiency on all patients diagnosed with EC $<60$ years; to date, $3 / 8$ patients tested have had MMR deficient tumours, all with loss of MLH1/ PMS2. All 3 were relatively young at age of diagnosis (32, 34 and 56 years respectively); the latter died prior to germline testing. The remaining 2 will be referred to Genetics for germline testing to ascertain if these represent Lynch syndrome or somatic mutations. Of note, the $32 \mathrm{yr}$ old was treated with an anti-PD-L1 agent after progressing through three lines of chemotherapy. She had an excellent response to this agent of several month duration, before recently progressing again.

\section{Conclusion}

The MMR pathway has long offered patients a simple screening test to identify those at risk of carrying a mutation in a cancer susceptibility gene as the cause for their cancer, but now additionally offers a promising research field for improving patient management by directing therapeutic op- 
tions, as well as potentially being able to inform prognosis While the data for the use of immunotherapy in those with MMR deficiency is currently limited, and further studies are required to confirm the benefit, this offers a potential biomarker for the selection of patients most likely to respond to immunotherapy, allowing targeted treatment that to date has been lacking in EC. Further studies into the prognostic implications of MMR deficiency are also required, as clear evidence of whether these patients have higher or lower risks of recurrence compared to those with stage-matched sporadic EC will also inform the need for aggressive adjuvant chemotherapy. Until a consensus on this is reached, the prognostic implications of MMR deficiency will remain controversial. Finally, as the management implications of

\section{References}

1. American Cancer Society: cancer facts and figures 2015. Atlanta, Ga: American Cancer Society; 2015. Available online (Last accessed July 1, 2015).

2. Lindemann K, Vatten LJ, Ellstrom-Engh M, Eskild A. Body mass, diabetes and smoking, and endometrial cancer risk: a follow-up study. Br J Cancer 2008;98(9):1582e5.

3. Collaborative Group on Epidemiological Studies on Endometrial Cancer. Endometrial cancer and oral contraceptives: an individual participant meta-analysis of 27276 women with endometrial cancer from 36 epidemiological studies. Lancet Oncol 2015 Sep; 16(9):1061e70.

4. Bokhman JV. Two pathogenetic types of endometrial carcinoma. Gynecol Oncol 1983 Feb;15(1):10e7.

5. Murali R, Soslow RA, Weigelt B. Classification of endometrial carcinoma: more than two types. Lancet Oncol 2014; 15(7):e268-78.

6. Iyer RR, Pluciennik A, Burdett V, Modrich PL. DNA mismatch repair: functions and mechanisms. Chem Rev 2006;106:302-23.

7. Thibodeau SN, Bren G, Schaid D. Microsatellite instability in cancer of the proximal colon. Science 1993; 260:816-9.

8. Gurin CC, Federici MG, Kang L, Boyd J. Causes and consequences of microsatellite instability in endometrial carcinoma. Cancer Res 1999;59:462-6.

9. Simpkins SB, Bocker T, Swisher EM et al. MLH1 promoter methylation and gene silencing is the primary cause of microsatellite instability in sporadic endometrial cancers. Hum Mol Genet 1999;8:661-6.

10. Bronner CE, Baker SM, Morrison PT et al. Mutation in the DNA mismatch repair gene homologue hMLH1 is associated with hereditary non-polyposis colon cancer. Nature 1994;368:258-61.

11. Fishel R, Lescoe MK, Rao MR et al. The human mutator gene homolog MSH2 and its association with hereditary nonpolyposis colon cancer. Cell 1993;75:1027-38.

12. Miyaki M, Konishi M, Tanaka K et al. Germline mutation of MSH6 as the cause of hereditary nonpolyposis colorectal cancer. Nat Genet 1997;17:271-2.
MMR deficient EC increase, so too will the reasons for performing universal testing of ECs, to ensure all those who would benefit from changes in management are able to be detected.

\section{Acknowledgments}

The authors thank Ray Hill, an independent medical writer, who provided native English editing and journal styling on behalf of HPS. This editorial assistance was funded by PharmaMar, Spain.

\section{Conflicts of Interest}

The Authors declare there are no conflicts of interest in relation to this article.

13. Nicolaides NC, Papadopoulos N, Liu B et al. Mutations of two PMS homologues in hereditary nonpolyposis colon cancer. Nature 1994;371:75-80.

14. Shia J, Ellis NA, Klimstra DS. The utility of immunohistochemical detection of DNA mismatch repair gene proteins. Virchows Arch 2004;445:431-41.

15. De Jong AE, Van Puijenbroek M, Hendriks Y et al. Microsatellite instability, immunohistochemistry, and additional PMS2 staining in suspected hereditary nonpolyposis colorectal cancer. Clin Cancer Res 2004;10:972-80.

16. Xicola RM, Llor X, Pons E et al; GastrointestinalOncology Group of the Spanish Gastroenterological Association. Performance of different microsatellite marker panels for detection of mismatch repair-deficient colorectal tumors. J Natl Cancer Inst 2007;99:244-52.

17. Cicek MS, Lindor NM, Gallinger S et al. Quality assessment and correlation of microsatellite instability and immune-histochemical markers among population- and clinic-based colorectal tumors results from the Colon Cancer Family Registry. J Mol Diagn 2011;13:271-81.

18. De Vos M, Hayward BE, Picton S et al. Novel PMS2 pseudogenes can conceal recessive mutations causing a distinctive childhood cancer syndrome. Am J Hum Genet 2004;74:954-64.

19. Hempelmann JA, Scroggins SM, Pritchard CC, Salipante SJ. MSI plus for integrated colorectal cancer molecular testing by Next-Generation Sequencing. J Mol Diagn 2015;17(6):705-14.

20. Pritchard CC, Smith C, Salipante SJ et al. ColoSeq provides comprehensive lynch and polyposis syndrome mutational analysis using massively parallel sequencing. J Mol Diagn 2012;14:357-66.

21. Warthin A. Heredity with reference to carcinoma as shown by the study of the cases examined in the Pathological Laboratory of the University of Michigan, 1895-1913. Arch Intern Med 1913;12:546-55.

22. Aarnio M, Sankila R, Pukkala E et al. Cancer risk in mutation carriers of DNA-mismatch-repair genes. Int J Cancer 1999;81:214-8. 
23. Watson P, Vasen HF, Mecklin JP et al. The risk of extracolonic, extra-endometrial cancer in the Lynch syndrome. Int J Cancer 2008;123:444-9.

24. Quehenberger F, Vasen HF, van Houwelingen HC. Risk of colorectal and endometrial cancer for carriers of mutations of the hMLH1 and hMSH2 gene: correction for ascertainment. J Med Genet 2005;42:491-6.

25. Casilli F, Tournier I, Sinilnikova OM et al. The contribution of germline rearrangements to the spectrum of BRCA2 mutations. J Med Genet 2006;43:e49.

26. Bonadona V, Bonaiti $\mathrm{B}$, Olschwang $\mathrm{S}$ et al. Cancer risks associated with germline mutations in MLH1, MSH2, and MSH6 genes in Lynch syndrome. JAMA 2011;305:2304-10.

27. Lynch HT, de la Chapelle A. Genetic susceptibility for nonpolyposis colorectal cancer. J Med Genet 1999;36:801-18.

28. Hampel H, Frankel WL, Martin E et al. Screening for the Lynch syndrome (hereditary nonpolyposis colorectal cancer. N Engl J Med 2005;352:1851-60.

29. Hampel H, Frankel W, Lockman J et al. Screening for Lynch syndrome (hereditary nonpolyposis colorectal cancer) among endometrial cancer patients. Cancer Res 2006;66(15):7810-7.

30. Lin DI, Hecht JL. Targeted screening with combined age- and morphology-based criteria enriches detection of Lynch syndrome in endometrial cancer. Int J Surg Pathol 2016;24:297-305.

31. Vasen HF, Mecklin JP, Khan PM, Lynch HT. The International Collaborative Group on Hereditary Non-Polyposis Colorectal Cancer (ICG-HNPCC). Dis Colon Rectum 1991;34:424-5.

32. Vasen HF, Watson P, Mecklin JP, Lynch HT: New clinical criteria for hereditary nonpolyposis colorectal cancer (HNPCC, Lynch syndrome) proposed by the International Collaborative group on HNPCC. Gastroenterology 1999;116:1453-6.

33. Rodriguez-Bigas MA, Boland CR, Hamilton SR et al. A National Cancer Institute Workshop on hereditary nonpolyposis colorectal cancer syndrome: meeting highlights and Bethesda guidelines. J Natl Cancer Inst 1997;89:1758-62.

34. Umar A, Boland CR, Terdiman JP et al. Revised Bethesda Guidelines for hereditary nonpolyposis colorectal cancer (Lynch syndrome) and microsatellite instability. J Natl Cancer Inst 2004;96:261-8.

35. Backes FJ, Leon ME, Ivanov I et al. Prospective evaluation of DNA mismatch repair protein expression in primary endometrial cancer. Gynecol Oncol 2009;114(3):48690. Epub 2009 Jun 10.

36. Leenen CH, Van Lier MG, Van Doorn HC et al. Prospective evaluation of molecular screening for Lynch syndrome in patients with endometrial cancer $\leq 70$ years. Gynecol Oncol 2012;125(2):414-20. Epub 2012 Feb 1.

37. Esteller M, Levine R, Baylin SB et al. MLH1 promoter hypermethylation is associated with the microsatellite instability phenotype in sporadic endometrial carcinomas. Oncogene 1998;17:2413-7.

38. Hecht JL, Mutter GL. Molecular and pathologic aspects of endometrial carcinogenesis. J Clin Oncol 2006;24:4783-91.

39. Joehlin-Price AS, Perrino CM, Stephens J et al. Mismatch repair protein expression in 1049 endometrial carcinomas, associations with body mass index, and other clinicopathologic variables. Gynecol Oncol 2014 Apr;133(1):43-7.

40. Black D, Soslow RA, Levine DA et al. Clinico-pathologic significance of defective DNA mismatch repair in endometrial carcinoma. J Clin Oncol 2006;24:1745-53.

41. Kato M, Takano M, Miyamoto M et al. DNA mismatch repair-related protein loss as a prognostic factor in endometrial cancers. J Gynecol Oncol 2015;26:40-5.

42. Nelson GS, Pink A, Lee $\mathrm{S}$ et al. MMR deficiency is common in high-grade endometrioid carcinomas and is associated with an unfavorable outcome. Gynecol Oncol 2013;131:309-14.

43. Popat S, Hubner R, Houlston RS. Systematic review of microsatellite instability and colorectal cancer prognosis. J Clin Oncol 2005;23(3):609-18.

44. Maxwell GL, Risinger JI, Alvarez AA et al. Favorable survival associated with microsatellite instability in endometrioid endometrial cancers. Obstet Gynecol 2001; 97:417-22.

45. Bilbao C, Lara PC, Ramírez R et al. Microsatellite instability predicts clinical outcome in radiation-treated endometrioid endometrial cancer. Int J Radiat Oncol Biol Phys 2010 Jan 1;76(1):9-13.

46. Terada KY, Black M, Terada LH et al. Survival of endometrial cancer patients with lymphatic invasion and deficient mismatch repair expression. Gynecol Oncol 2013;129:188-92.

47. Fiumicino S, Ercoli A, Ferrandina G et al. Microsatellite instability is an independent indicator of recurrence in sporadic stage I-II endometrial adenocarcinoma. J Clin Oncol 2001;19(4):1008-14.

48. Mackay HJ, Gallinger S, Tsao MS et al. Prognostic value of microsatellite instability (MSI) and PTEN expression in women with endometrial cancer: results from studies of the NCIC Clinical Trials Group (NCIC CTG). Eur J Cancer 2010;46(8):1365-73.

49. Resnick KE, Frankel WL, Morrison CD et al. Mismatch repair status and outcomes after adjuvant therapy in patients with surgically staged endometrial cancer. Gynecol Oncol 2010;117:234-8.

50. Cohn DE, Frankel WL, Resnick KE et al. Improved survival with an intact DNA mismatch repair system in endometrial cancer. Obstet Gynecol 2006;108:1208-5.

51. Diaz-Padilla I, Romero N, Amir E et al. Mismatch repair status and clinical outcome in endometrial cancer: A systematic review and meta-analysis. Crit Rev Oncol Hematol 2013;88:154-67.

52. Watson P, Lynch HT. Cancer risk in mismatch repair gene mutation carriers. Fam Cancer 2001;1:57-60.

53. Llosa NJ, Cruise M, Tam A et al. The vigorous immune microenvironment of microsatellite instable colon cancer is balanced by multiple counter-inhibitory checkpoints. Cancer Discov 2015;5(1):43-51.

54. Dudley JC, Lin MT, Le DT, Eshleman JR. Microsatellite instability as a biomarker for PD-1 blockade. Clin Cancer Res 2016;22:813-20.

55. Le DT, Uram JN, Wang H et al. PD-1 blockade in tumors with mismatch-repair deficiency. N Engl J Med 2015; 372(26):2509-20. 
56. Howitt BE, Shukla SA, Sholl LM et al. Association of polymerase e-mutated and microsatellite-instable endometrial cancers with neoantigen load, number of tumorinfiltrating lymphocytes, and expression of PD-1 and PDL1. JAMA Oncology 2015;1(9):1319-23.

57. Fink D, Nebel S, Aebi S et al. The role of DNA mismatch repair in platinum drug resistance. Cancer Res 1996;56:4881-6.

58. Helleman J, van Staveren IL, Dinjens WN et al. Mismatch repair and treatment resistance in ovarian cancer. BMC Cancer 2006;6:201.
59. Marcelis CL, van der Putten HW, Tops C et al. Chemotherapy resistant ovarian cancer in carriers of an hMSH2 mutation? Fam Cancer 2001;1:107-9.

60. Martin SA, McCarthy A, Barber LJ et al. Methotrexate induces oxidative DNA damage and is selectively lethal to tumour cells with defects in the DNA mismatch repair gene MSH2. EMBO Mol Med 2009;1:323-37.

61. Boland CR, Shike M. Report from the Jerusalem workshop on Lynch syndrome-hereditary nonpolyposis colorectal cancer. Gastroenterology 2010;138:2197.e2191-7. 